\title{
FACTORS INFLUENCING DIETARY CHOICES OF IMMIGRANTS UPON RESETTLEMENT IN HOST COUNTRIES - A SCOPING REVIEW
}

\author{
DwebA, T. P. - Oguttu, W. J. - MbajIORGU, C. A.* \\ Department of Agriculture and Animal Health, University of South Africa \\ Florida Science Campus, Johannesburg, P. O. BOX 392, UNISA 0003, South Africa \\ *Corresponding author \\ e-mail:mbajica@unisa.ac.za \\ (Received $6^{\text {th }}$ Sep 2017; accepted $20^{\text {th }}$ Dec 2017)
}

\begin{abstract}
The adverse effects of migration on eating habits are well documented. Accessing healthy, culturally appropriate food is essential for achieving food security and overall health. However, less is known about the factors that affect post-immigration dietary choices. This scoping review assesses current findings regarding factors determining dietary choices. Electronic databases of papers published between 2005 and 2015 were used to retrieve and review papers for this review. Titles were reviewed by three reviewers to select papers that met the inclusion criterion set for this paper. A total of 50 papers were eventually selected and included in the review. Based on the work done in South Africa and internationally, various factors that affect dietary choices of immigrants were identified and include: climate change related factors, socio-economic factors, difficulty in navigating the new shopping environment, immigrant's perceptions towards host country's food, language barriers, failure to access traditional ingredients, safety of food sold in the ethnic markets, pressure from children to adopt host country's food and role of religion in determining immigrant's food choices in host countries. Findings of this study demonstrate that there are major research gaps on dietary patterns of sub-Saharan African immigrants, and identifies research priorities in this field.
\end{abstract}

Keywords: ethnic food markets, traditional food ingredients, food safety, food insecurity, food accessibility

\section{Introduction}

According to the 1996 World Food Summit "Food security is a condition that exists when all people, at all times, have physical and economic access to sufficient, safe, and nutritious food to meet their dietary needs and food preferences for an active and healthy life" (FAO, 2006). This therefore means that accessing healthy, culturally appropriate food is essential for food security to be realized by any immigrant (Jacobus and Jalali, 2011; Vahabi and Damba, 2013) hence migrating into a new country with different food culture, poses dietary challenges.

Loss of food products and food consumption patterns is one of the major challenges faced by immigrants upon resettlement in host countries (Njomo, 2013). This is attributed to the fact that apart from its nutritious role, food has religious, cultural and social roles among native people. As a result, in different countries, there are distinct variations in what is considered edible (Hadley et al., 2010; Dharod et al., 2011; Garnweidner et al., 2012; Mannion et al., 2014).

The challenges encountered often result in adopting unhealthy eating habits and subsequent decline in nutritional health of the immigrants (Renzaho and Burns, 2006; Satia, 2010; Kiptinness and Dharod, 2011; Okafor et al., 2014; Terragni et al., 2014). The unhealthy eating habits are known to lead to the loss of what is known as "Healthy Immigrant Effect" (HIE) (Sanou et al., 2014), a term that refers to a phenomenon in 
which immigrants are habitually healthier than the natives of the host country. This is because immigrants are forced to undergo high dietary acculturation; whereby they adopt eating habits of their host country. The result, is a rapid decline in the HIE upon settlement in the host countries. Several authors have shown that acculturation whenever it occurs, is associated with adopting unhealthy eating habits (Renzaho and Burns, 2006; Satia, 2010; Kiptinness and Dharod, 2011; Okafor et al., 2014; Terragni et al., 2014). This is because the resulting dietary changes are habitually associated with high intake of fat, salt and refined cereals (Dharod et al., 2011). This places immigrants at an increased risk of developing chronic diseases of the lifestyle (Deng et al., 2013; Sanou et al., 2014).

While dietary acculturation among immigrants upon resettlement in host countries is common, generally immigrants prefer to maintain their original food culture (Kiptinness and Dharod, 2011; Vue et al., 2011; Garnweidner et al., 2012; Lesser et al., 2014; Lindsay et al., 2014). As a result, majority of immigrants tend to develop bicultural eating patterns (Vue et al., 2011; Garnweidner et al., 2012).

Given the issues raised in the paragraph above, it is evident that immigrants moving to new countries do face unique dietary challenges which have potential to impact on their health and wellbeing while in their new home. In light of this, the question that arises is what determines immigrants' dietary choices upon settlement, and what dietary related challenges do they encounter in the host countries?

Recent immigration trends indicate that majority of African international migration takes place within the continent. It is reported that about $70 \%$ of all international migrations are intra-regional (Ratha and Shaw, 2007; Adepoju, 2008; Njomo, 2012). The number of immigrants from Sub-Saharan Africa to South Africa has been on the increase due to unstable economic conditions, soaring ethnic conflicts, and volatile political situations in most African countries (Adepoju, 2008; Njomo, 2013; Statistics South Africa, 2013). Besides war and harsh economic conditions prevailing in a number of African countries, climate change, which results into environmental effects such as loss of arable land, negative impact on the ecosystem and loss of natural environments, which, societies depend on, plays an important role in migration of people from one country to another (McMichael, 2012).

Official reports based on the 2011 census, suggested that there are approximately 2.2 million recorded immigrants in South Africa (Wilkinson, 2015; Chiumia, 2016); however this number could be more due to illegal immigrants and the fact that figures suggest that the number of permits that are issued are increasing every year (Statistics South Africa, 2014b). A major part (70\%) of these immigrants are from African countries (Wilkinson, 2015). Immigrants living in South Africa are predominantly from Zimbabwe (42.6\%), the Democratic Republic of Congo (12.9\%), Nigeria (10.3\%), and Lesotho (4.7\%). The remaining 29.5\% are from Rwanda, Burundi, Cameroon, Kenya, Tanzania, Uganda, Eritrea, Ethiopia, Somalia, Cote D'Ivoire, Gabon, Ghana, Niger, Sierra Leone, Togo, Angola, Botswana, Lesotho, Malawi, Mozambique, Namibia and Zambia (South African Press Association, 2014). According to Njomo (2013): these immigrants come to South Africa in search of better living conditions.

Despite these statistics, little is known about sub-Saharan African intra-regional immigrant dietary patterns, challenges and nutritional health. Therefore, the aim of this review was to highlight challenges faced by immigrants in accessing healthy, culturally appropriate food, and the possible impact this may have on the immigrants' dietary patterns upon resettlement in host countries. This review also identified 
knowledge gaps and research priorities related to sub-Saharan African immigrant's dietary patterns who have migrated within the continent. Although this paper covers factors affecting a range of immigrants, a special emphasis is placed on sub-Saharan immigrants. Furthermore research gaps and priorities identified are specific to subSaharan immigrants in South Africa.

\section{Methodology}

A scoping review was undertaken to explore studies that had been undertaken on food related challenges experienced by immigrants upon resettlement in their host countries. In line with the objectives of a scoping review discussed by Arksey and O'Malley (2005) there was no consideration to study designs or quality of the studies. This review was undertaken to evaluate the type and extent of the research that has been undertaken, to summarize research findings and identify research gaps.

Different sources such as electronic databases and reference lists were utilised to identify relevant studies. Only studies published from January 2005 to April 2015 were included in this review. Research conducted prior to this date was deemed unlikely to reflect current research trends. Secondly, only studies published in English were considered due to costs involved in translation. The first step involved identification of all relevant articles using key words. This process yielded a large number of irrelevant articles. An initial screening yielded 2,720 articles. Papers that did not meet the inclusion criterion were discarded. An inclusion criterion was then refined to narrow down the number of articles. This inclusion criterion included papers related to factors determining dietary choices of sub-Saharan immigrants.

Titles were screened by three reviewers for relevance and those titles that did not fit the criterion were discarded. Copies of full articles that appeared to meet the set criteria were downloaded and saved in Mendeley. Copies of full articles that were not accessible were also excluded. After reviewing titles only 108 articles were retained. The abstracts for these papers were then reviewed, and out of the 105 articles that were retrieved from the electronic searches, 24 papers were selected for the review. From the 24 articles that were identified, reference lists were then utilised to identify further studies. Furthermore, papers citing any of the selected papers were also reviewed for relevance. Although the main focus of the review was sub-Saharan immigrants, at this stage in cases whereby there was paucity of studies; relevant citing papers including other immigrant groups were also included. From this process, 11 articles from the references and 15 citing articles were selected for inclusion. In total 50 papers were retrieved and included in the review. The process and results of the retrieval are summarized in Figure 1.

Each article was reviewed extensively and relevant information was recorded using Microsoft Excel. This included information on the study population, sample size, study area, and major findings (Appendix). The information was then analysed by the three authors using a narrative synthesis. The information was then organised thematically into eight factors affecting dietary choices. These factors include climate change barriers, socio-economic status, difficulty in navigating the environment, perceptions towards the host country's food, language barriers, accessibility of traditional food ingredients, safety of the food from the ethnic markets, pressure from children to adopt host country's food culture, and religious factors. 


\section{2,720 articles retrieved from the initial screening}

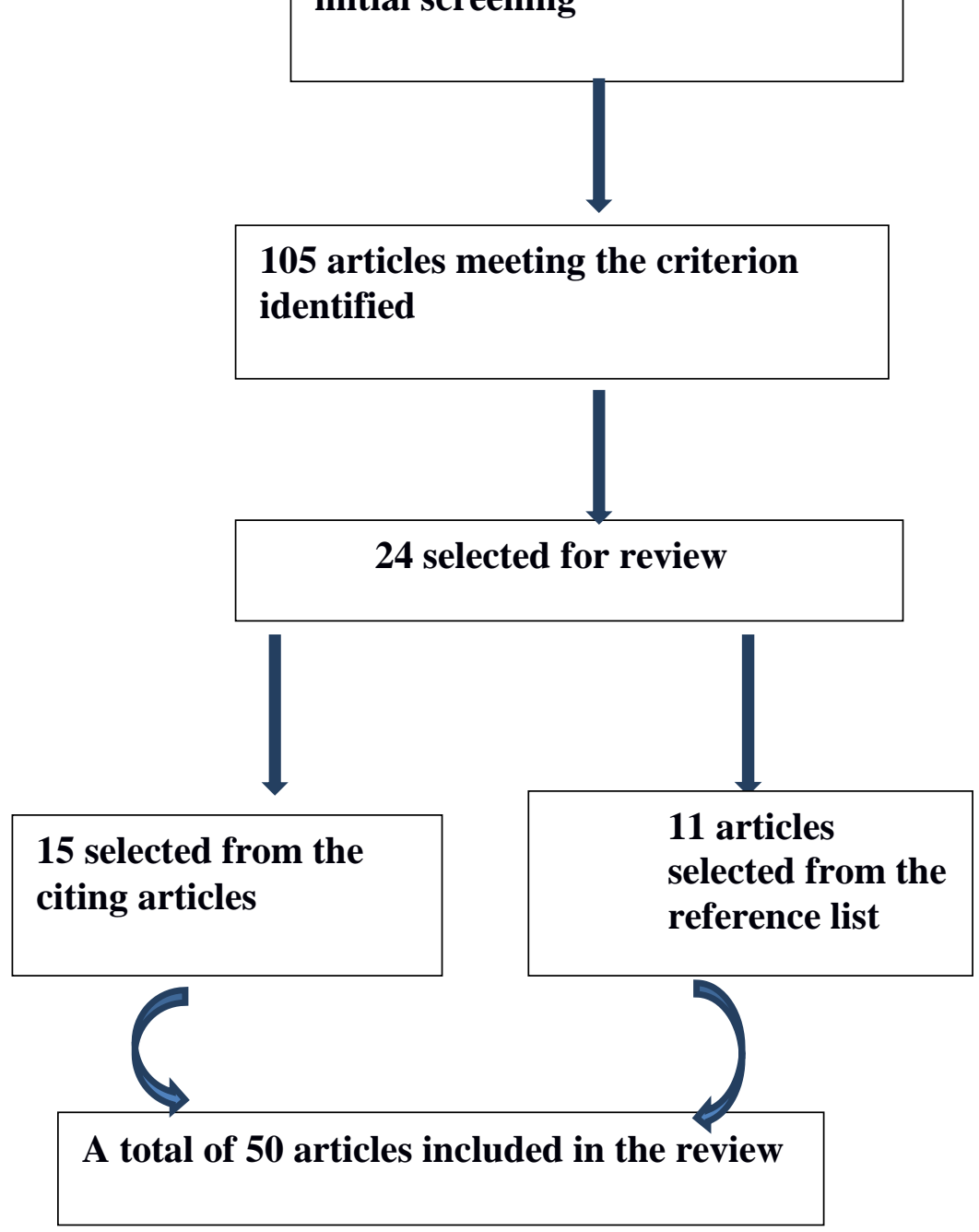

Figure 1. The methodological framework of how literature used in this paper was selected

\section{Climate change related barriers}

Apart from being the causal effect of migration, climate change can also be the driver of many food related challenges that immigrants encounter in host countries or destinations (McMichael et al., 2012; McMichael, 2015). Climate change driven migration is usually abrupt, therefore its aftermaths are comparable to those of refugees, as the affected usually have limited choice of their destination; with some ending up in developing countries that have limited resources (McMichael et al., 2012). In cases where climate change related migration results in large-scale population displacements, people often end up in settlements that are crowded, poorly ventilated, and with poor sanitation, resulting in adverse food related challenges (McMichael et al., 2012; Pendleton et al., 2014).

Firstly, as mentioned above, overpopulation that results from climate change driven migration leads to loss of arable land and natural environments that societies depend on for their well-being, thus affecting agricultural productivity not only for the immigrants but for native communities as well (McMichael et al., 2012). As the population grows; 
forests, swamps, lakes and other habitats are cleared for residential areas, causing loss of biodiversity thus affecting lives and livelihoods of those that are directly dependent on healthy ecosystems (Berjak et al., 2011). Inadequate arable land combined with loss of biodiversity in turn forces immigrants who mostly originate from rural areas to depend mainly on shops for access of food, making them vulnerable to price fluctuations.

Secondly, conditions alluded to in the previous section can result into outbreaks of disease such as cholera, typhoid hepatitis A, measles, respiratory diseases, diarrheal diseases and malaria (McMichael et al., 2012). Apart from putting pressure on the health system that is already under siege due to overcrowding, such diseases decrease productivity and earning capacity thus negatively affecting economic resources for accessing food (WHO, 2013).

\section{Socio-economic causes}

According to Hadley et al. (2010) and Sanou et al. (2014), socio-economic status of immigrants is major mediating factor to food insecurity. This is associated with lower incomes and low employment levels (Hadley et al., 2010; Vahabi and Damba, 2013; Anderson et al., 2014). This phenomenon is even higher amongst refugees as they are characterized with lack of formal education, language barriers, and lower employment levels (Hadley et al., 2010; Kiptinness and Dharod, 2011; Anderson et al., 2014). Lack of education makes it difficult for immigrants to find employment thus limiting their financial resources and hence the vulnerability to food insecurity (Kiptinness and Dharod, 2011; Vahabi and Damba, 2013; Anderson et al., 2014). For example in a study by Kiptiness and Dharod (2010) conducted in United States amongst Bhutanese refugees, about $64 \%(n=9)$ of the participants had no formal education. As a result only $14 \%(\mathrm{n}=2)$ of them were able to get part-time or fulltime employment. Hadley et al. (2010) who studied Somali refugees also found similar results. The majority of the households of the Somali refugees that participated in their study had lower monthly household incomes. Vahabi and Damba (2013) also came to the same conclusion, stating that the majority of Latin American immigrants in their study had low income due to difficulties in finding decent jobs. Anderson et al. (2014) observed that about $71 \%(\mathrm{n}=35)$ who had experienced food insecurity were of a low education and income status. The latter study by Anderson et al. (2014) was conducted amongst Sudanese refugees. In study done in Ghana, more than half of the Liberian refugees (51.9\%; $\mathrm{n}$ $=124$ ) based in Buduburam, were not employed (Ross, 2016).

In literature low employment levels of immigrants has been associated with inability to speak the host country's official language (Shackelford, 2010; Vahabi and Damba, 2013; Anderson et al., 2014). It is reported that those that have language difficulties face increased and long-term disadvantages due to limited employment prospects. This is despite their education level (Shackelford, 2010). According to Vahambi and Damba (2013), language difficulties were a major hindrance to employment amongst Latin American immigrants. This is despite the fact that majority were well educated and had extensive work experience. Majority of these immigrants were either unemployed or holding low-paying or seasonal jobs. This phenomenon is consistent with findings of a study by Anderson et al. (2014), which showed that language barriers had a bearing on low employment levels among immigrants. It is reported that the low employment 
levels is aggravated by the imposed employment restrictions on foreign nationals (Shackelford, 2010).

Several authors suggest that food insecurity is highly prevalent amongst immigrants especially sub-Saharan immigrants (Dharod et al., 2011; Jacobus and Jalali, 2011; Anderson et al., 2014). The situation is worse for the newly settled immigrants and refugees (Hadley et al., 2010). In a study conducted in Midwestern United States amongst refugees by Hadley et al. $(2010), 78 \%(n=218)$ of the respondents revealed that they had experienced food insecurity. The refugees in the study by Hadley et al. (2010) came from countries like Sierra Leone, Liberia, Somali, Ghana, Somali, Togo and Meskhetian Turk. Dharod et al. (2011) also confirmed these results in a pilot study conducted amongst Somali refugees living in United States. These authors reported that $72 \%(\mathrm{n}=25)$ of the study population were food insecure. Another study conducted amongst African Immigrants in Lewiston also revealed major challenges with regards to food access (Jacobus and Jalali, 2011). According to Vahambi and Damba (2013) a low socio-economic status impacts on a household's ability to access adequate food by altering quality and quantity of food purchases (Vahabi and Damba, 2013).

Furthermore, several researchers (Dharod et al., 2013; Anderson et al., 2014; Sanou et al., 2014) show that households of low socio-economic status tend to adopt unhealthy dietary transitions. An illustrated example is the observation by Anderson et al. (2014) on Sudanese in United States who replaced high-cost and micro-nutrient dense food items with cheaper energy-dense, processed food and snacks. This form of dietary change is unhealthy because it lacks dietary diversity and results in excessive consumption of energy and unhealthy fats. These inappropriate dietary changes are associated with weight gain, development of type 2 diabetes, cardiovascular diseases and other nutrition related problems (Schönfeldt and Hall, 2012).

Studies indicate that due to the high levels of food insecurity within the immigrant communities, majority of immigrants end up depending on social support programmes (Dharod et al., 2011, 2013; Jacobus and Jalali, 2011; Anderson et al., 2014). These food assistance programs vary from one area to the other. Some offer money to unemployed immigrants, while others offer food items (Vahabi et al., 2011). However, it has been shown that social support programmes are not able to solve the problem of food insecurity among immigrants (Dharod et al., 2011; Vahabi et al., 2011; Anderson et al., 2014). For example, Dharod et al. (2011) showed that 55\% $(n=19)$ of the households that received social support once a month, reported that the benefit lasted for less than a month, which renders them vulnerable to food insecurity. Vahambi and Damba (2013), who showed that the majority of respondents who received money from the state welfare programme could not meet their household food costs, confirmed this. Furthermore, Anderson et al. (2014) reported that social support programmes were insufficient, by noting that recipients were unable to cover their food and housing costs. In fact, according to some authors, the prevalence of food insecurity tends to be higher among the beneficiaries of social support programmes (Dharod et al., 2011; Vahabi et al., 2011; Vahabi and Damba, 2013).

Studies that have been conducted in United States and Canada indicate that, food assistance programs lack cultural sensitivity (Jacobus and Jalali, 2011; Vahabi et al., 2011; Vahabi and Damba, 2013). This lack of cultural sensitivity often leads to food banks and shelters supplying immigrants with limited and culturally inappropriate foods (Vahabi et al., 2011). For example, research has shown that immigrants often complained that food banks supplied them with unfamiliar foods (Vahabi et al., 2011; 
Vahabi and Damba, 2013). These unfamiliar foods included canned and dried foods which immigrants were unable to prepare, as opposed to fresh foods to which immigrants are accustomed. Provision of culturally inappropriate food was also reported in shelters and soup kitchens (Jacobus and Jalali, 2011; Vahabi et al., 2011). As a result, majority of these programs failed to alleviate food insecurity amongst immigrants (Vahabi et al., 2011).

The findings presented here are strong evidence that socio-economic status of immigrants, which steadily decreases upon settlement in host countries, does negatively affect their food security status. The number of sub-Saharan immigrants in South Africa has been increasing over the years (Statistics South Africa, 2014a). For example, the 2011 census revealed that, $5.7 \%$ of the South African born population is foreign-born (Statistics South Africa, 2013). In addition to this, 6,801 permanent residence permits were approved in 2013, compared to 1,283 that were approved in 2012. Although the number for temporal residence has been fluctuating, over 100,000 permits per year were approved in 2011, 2012 and 2013 (Statistics South Africa, 2014b). This notwithstanding, there is no evidence of studies that have assessed the socio-economic and food security status of the growing population of immigrants in South Africa.

Although there is paucity of studies on sub-Saharan immigrants' socio-economic status in South Africa, studies conducted in other parts of the world suggest that the general trend is for immigrants to be of a low socio-economic status. Results of similar studies conducted on the African continent seem to suggest the same socio-economic trends. For example, Liberian immigrants residing in Ghana were unemployed and fell into the category of low or middle income earners (Ross et al., 2016). In South Africa, apart from the negative impact of the low economic status of immigrants on their food security status the situation could also negatively affect the health of immigrants. This could in turn place tremendous pressure on the South African public health system. To help mitigate this emerging burden, evidence based studies are required.

\section{Difficulty in navigating the new food environment}

Several challenges in navigating the new food environment have been widely documented in the literature as risk factors to food insecurity and unhealthy eating habits among immigrants (Hadley et al., 2010; Kiptinness et al., 2011; Dharod et al., 2011; Mannion et al., 2014; Terragni et al., 2014). The challenges of navigating the new food environment that have been recorded in various literature include unfamiliar food purchasing environment, unfamiliar food items, and cooking practices. This group of factors that are classified as non-income related factors, aggravate food insecurity among immigrants who by virtue of low household incomes are prone to food insecurity (Hadley et al., 2010; Dharod et al., 2011; Mannion et al., 2014; Terragni et al., 2014).

Unfamiliar shopping environment has also been identified as one of the causes of shopping difficulties amongst immigrants upon resettlement. Large supermarkets are reportedly one of the most prominent overwhelming features that immigrants are confronted with upon immigration (Hadley et al., 2010; Kiptinness et al., 2011; Terragni et al., 2014; Wilson and Renzaho, 2014). This is attributed to the fact that most immigrants are accustomed to small shops and open markets back in their countries of origin. In such environments, immigrants find it difficult to locate and identify items thus curtailing their shopping capabilities (Hadley et al., 2010; Njomo, 2012; Terragni et al., 2014). 
Furthermore, most large supermarkets sell mainly frozen and processed foods, as opposed to fresh foods that most immigrants are familiar with (Hadley et al., 2010; Terragni et al., 2014). This becomes a challenge because most immigrants do not know how to incorporate these foods in their meals. Additionally supermarkets found in host countries are characterised by food that is packaged and wrapped, which makes it difficult to identify the food items (Terragni et al., 2014; Wilson and Renzaho, 2014). This coupled with language barriers, leads to most food items being excluded as it forces immigrants to stick to their traditional foods and thus restricting the variety of food being consumed (Hadley et al., 2010).

Some researchers (Hadley et al., 2010; Kiptinness and Dharod, 2011; Dharod et al., 2013; Terragni et al., 2014; Wilson and Renzaho, 2014) argue that even in countries where the large supermarkets do stock ethnic foods, majority of immigrants still prefer to buy from the small ethnic retailers. This is could be due to the overwhelming environment in the supermarkets or due to cultural familiarity, familiarity with the language and trust as small ethnic shops are usually owned by fellow countrymen (Dharod et al., 2013). Additionally the ethnic shops offer more than just ethnic foods, they act as social centres where immigrants can meet friends and socialize, cultural consultants, and information sharing centres (Jacobus and Jalali, 2011; Njomo, 2013). However, this is contrary to what was observed in South Africa, where Njomo (2013) observed that majority of sub-Saharan African immigrants who participated preferred to buy their ethnic foods from the mainstream supermarkets. In fact, these respondents indicated that they regularly patronise major supermarket chains such as Shoprite, Pick n Pay, Checkers, Spar and Woolworths to source food. The above observation is attributed to the belief that supermarkets tend to sell cheaper, offer a wide variety and good quality products. Given that this observation was made in only study that was limited in scope, the view that immigrants prefer mainstream supermarkets over ethnic food retailers deserves further investigation to ascertain if it is the general trend.

Unfamiliar food items have also been identified as further barriers to accessing adequate food amongst immigrants in host countries. The problem here is lack of knowledge on how to prepare and include these new foods in their diets (Hadley et al., 2010; Mannion et al., 2014; Sanou et al., 2014; Terragni et al., 2014). For example, in South Africa it has been reported that sub-Saharan immigrants often complain that food sold in the large supermarkets is not familiar and is new especially to those that have just relocated (Njomo, 2012). Of the 281 immigrants surveyed by Hadley et al. (2010); $40 \%(\mathrm{n}=111)$ indicated that they were not familiar with food sold in the shops, and $63 \%(\mathrm{n}=169)$ indicated they did not know how to prepare it. This is complicated by the fact that in most cases immigrant women associate the term "safe" food with known foods (Mannion et al., 2014). Based on the experiences of Sudanese refugee women, navigating a new food environment, Mannion et al. (2014) suggests that immigrant women are often reluctant to try new foods due to lack of trust, knowledge, and not knowing how these foods are prepared. In the study by Mannion et al. (2014), a nutrition resource that was developed to assist Sudanese women with the selection of healthy foods, failed because apart from using a foreign language it also contained mainly food items that were unfamiliar to the group. This suggests that generally new foods create distrust and uncertainty about safety of foods. This uncertainty and mistrust reduces the number of food items available to immigrants especially when familiar food is not available (Terragni et al., 2014). 


\section{Immigrant's perceptions towards host country's food}

Immigrants' perceptions towards host country's food culture has been observed to play a major role in determining the adoption of the food culture of the host country. According to Garnweidner at al. (2012), immigrants tend to compare their original food culture to that of the host country and make clear differentiation between them. Consequently terms such as "our food" when referring to their original food and "their food" when referring to host country's food are often used. Based on their cultural and religious beliefs they then decide if the food is culturally appropriate or inappropriate. From available literature it seems that reasons for negative perceptions vary from one person to the other. In previous studies by Garnweidner et al. (2012) and Vahabi and Damba (2013), negative perceptions were caused by differences in taste while according to Mannion (2014), they were caused by distrust of the new food. However, despite the reasons, negative perceptions lead to rejection of the host country's food culture (Vahabi and Damba, 2013; Garnweidner et al., 2012).

A typical example of this is illustrated by a study that was conducted amongst Hmong women residing in United State that reported that most immigrants' mothers perceived host country's food to be unhealthy and less filling (Vue et al., 2011). A study conducted in Norway amongst African and Asian immigrants also showed that the immigrants had negative perceptions of the host country's food culture. The study showed that the host country's food was perceived as tasteless, not filling and lacking nutrients. Because of these negative perceptions, the host country's food was sometimes not considered as food by immigrants but as snack (Vue et al., 2011; Garnweidner et al., 2012). The negative perceptions were also observed by Vahabi and Damba (2013), in a study that was conducted in Canada amongst Spanish/Portuguese immigrants who indicated that the quality, taste and smell was different from what they were used to. Furthermore, immigrants in the study by Vahabi and Damba (2013) believed that Canadian food posed health hazards especially to children. They also complained of the poor nutritional value, high fat and salt content of the food. As a result, Canadian food was deemed culturally inappropriate. Based on these findings it is apparent that, how immigrants perceive the host nation's food is one of the major barriers to food acquisition amongst immigrants. Therefore, in the absence of original food ingredients, this has the potential to impact on the food security of the immigrant community.

Mannion et al. (2014) also observed the same phenomenon in their study, and indicated that Sudanese refugees residing in Canada excluded most food items from their diets because they associated host country's food with obesity due to its perceived high fat content. Probably unbeknown to them, the fear of obesity has a scientific basis related to the fact that it is associated with the development of noncommunicable diseases (NDCs) such as cancers, cardiovascular diseases, chronic respiratory diseases and diabetes. NCDs increase health care costs, depletes household resources, slows down poverty reduction initiatives (Schönfeldt and Hall, 2012; WHO, 2014) and results into premature deaths (WHO, 2014). In 1990, NCDs were responsible for $27 \%$ of the total death rate. This rate is expected to escalate to $50 \%$ in developing countries by 2020 (Schönfeldt and Hall, 2012). It is further reported that NCDs were the leading cause of deaths globally, accounting for $68 \%$ of the world's 56 million deaths in 2012 (WHO, 2014).

Apart from social assistance programs lacking in cultural sensitivity as discussed earlier, negative perceptions to these programmes also affect nutrition education and health promotion programs (Garnweidner et al., 2012). For example, as was alluded 
to in the previous section; a nutrition resource, which was meant to be a nutrition education resource tool for immigrants proved ineffective. One of the reasons for the failure of this nutrition resource tool was the fact that Canadian foods that were used as examples were considered to be unhealthy by immigrants. Vue et al. (2011) and Garnweidner et al. (2012) argue that nutrition messages become ineffective when they are not customized and are culturally insensitive. Cultural sensitivity is described as the ability to acknowledge the differences that exist within cultures by tailoring and respecting these when encountering diverse groups and individuals (Garnweidner et al., 2012).

Therefore, negative perceptions could have serious implications on immigrants being food secure especially where there is scarcity or difficulty in accessing their original food in the host countries. This emerged in a study that was conducted amongst Sudanese refugees residing in United States, whereby a large proportion of those that experienced higher levels of household food insecurity preferred traditional food (Anderson et al., 2014). This means that health practitioners need to be cognisant of immigrant's food culture and incorporate this knowledge when designing and implementing nutrition programs. This will enable health care professionals to design tailor made communication messages that take into account background, religious beliefs and context (Garnweidner et al., 2012). In countries like South Africa where immigrant's dietary patterns have not been established (Njomo, 2012), future studies on immigrant's food culture are necessary. Such studies should look at immigrant's perceptions towards host country's food culture. In addition to learning the immigrant's perspectives; ethnic food markets and restaurants can be used as case studies to learn and understand immigrants' food culture.

\section{Language barrier}

Inability to speak the host country's official language has been associated with food insecurity amongst immigrants in previous studies (Hadley et al., 2010; Vahabi et al., 2011; Vahabi and Damba, 2013; Anderson et al., 2014). Studies show that, immigrants that experience language barrier experience high levels of food insecurity (Hadley et al., 2010; Vahabi and Damba, 2013). Studies also reveal that language difficulties directly affect immigrant's ability to access food by restricting shopping choices (Vahabi and Damba, 2013), their ability to read labels (Hadley et al., 2010) and benefit from promotional information such as discounts and coupons (Vahabi et al., 2011; Vahabi and Damba, 2013).

According to (Vahabi and Damba, 2013) not being proficiency in English restricted the number of shops immigrants utilised to buy their groceries. Results of the study by Vahabi and Damba (2013) indicated that respondents avoided small convenience stores due to language difficulties. Instead, they preferred large chain stores where they could search for food items independently without seeking assistance from shopkeepers. This could have negative implications for food security in cases where chain stores are located far away from residential areas. This is because proximity to the food source is a major determinant to food access (Jacobus and Jalali, 2011). In fact long distances to grocery shops is known to increase transportation costs and in this way negatively impacts on immigrants ability to access food (Vahabi and Damba, 2013).

Language barrier also results inability to read food items, nutritional labels, and selection of appropriate food to purchase (Hadley et al., 2010; Vahabi et al., 2011; 
Vahabi and Damba, 2013). For example, studies conducted amongst Latin Americans in Toronto, Canada, found that they struggled to understand ingredients and nutritional composition of foods, making it difficult to make healthy choices. The result could be restricted food choices and a decrease in the variety of foods consumed especially when access to traditional foods is limited. A similar study conducted in Canada amongst Sudanese women, confirmed these findings, revealing that difficulties in language impeded on their ability to recognise food (Mannion et al., 2014). This was further confirmed in a study conducted in Norway where women from South Asian, African, and Middle Eastern Countries found it difficult to read packaging information or ask for help from shop assistants (Terragni et al., 2014).

\section{Failure to access traditional ingredients in the host countries}

Available evidence suggests most immigrants prefer to maintain their traditional diets. However, they are unable to do so due to unavailability and inaccessibility of traditional ingredients (Renzaho and Burns, 2006; Garnweidner et al., 2012; Njomo, 2013; Vahabi and Damba, 2013; Sanou et al., 2014; Terragni et al., 2014). This in addition to the factors mentioned above has the potential to negatively affect the food security and nutritional status of immigrants. It forces them to replace their diets with unhealthy food items (Kiptinness and Dharod, 2011).

The unavailability of immigrant's food especially from the mainstream supermarkets has been reported in several host countries including South Africa, Canada, and North America (Deng et al., 2013; Dharod et al., 2013; Njomo, 2013; Vahabi and Damba, 2013). In South Africa, the unavailability of ethnic food ingredients has led to the emergence of ethnic shops and restaurants in main city centres around the country. However, these ethnic food shops are unable to stock sufficient amounts and a variety of foods (Njomo, 2013).

In South Africa, information on ethnic markets is scanty. Only one study could be sourced, and the study in question was limited in scope as it considered only immigrants in Cape Town. In view of this, studies in other provinces especially Gauteng which is home to the largest number of sub-Saharan immigrants in South Africa are needed. The authors are of view that such studies should assess the availability and accessibility of ethnic foods for the sub-Saharan immigrant community that is resident in South Africa.

Accessibility of traditional food ingredients is further exacerbated by the high prices of these foods in the host countries (Jacobus and Jalali, 2011; Deng et al., 2013; Njomo, 2013; Popovic-Lipovac and Strasser, 2015). The majority of immigrants, who participated in the study by Njomo (2013), indicated that ethnic foods for sub-Saharan immigrants living in South Africa are very expensive as compared to countries like Canada and America. The cause of the high prices is the unavailability of these traditional food ingredients from the major grocery stores (Njomo, 2013; Vahabi and Damba, 2013) and high export prices (Jacobus and Jalali, 2011; Njomo, 2012). This is a serious problem when one considers the fact that the majority of immigrants are often characterized by low incomes due to low employment levels. As a result the majority of immigrants tend to resort to consumptions of high-calorie, low-nutrient dense food (Kiptinness and Dharod, 2011; Vahabi and Damba, 2013). This trend is associated with weight gain and development of chronic diseases of the lifestyle (Kiptinness and Dharod, 2011; Popovic-Lipovac and Strasser, 2015). In view of this, there is a need to increase the availability and accessibility of immigrant's original 
food ingredients in host countries. However, to achieve maximum availability and accessibility of food by immigrants in question, there is a need for clear understanding of the food culture of immigrants. This will help stakeholders understand food preferences immigrants and how they would like to see the foods presented. This can be achieved through encouraging ethnic food business owners to form cooperatives or groups so that they can have greater buying power and be able to negotiate with the big suppliers (Jacobus and Jalali, 2011). Through cooperative buying these small businesses can also buy in bulk and pull resources together to curb transportation costs. They can also though cooperatives negotiate with local farmers to produce some of their food in the host country.

\section{Safety of food sold in the ethnic markets}

Food safety refers to a series of activities that are undertaken to prevent foodborne illnesses by ensuring safe handling, preparation and storage of food. Worldwide failure to comply with acceptable food safety standards is reportedly responsible for an estimated 2.2 million deaths annually especially within the poor communities (WHO, 2013). Furtherance to this, the effects of foodborne illnesses do not only threaten the life of individuals concerned, but also have adverse economic consequences on communities, businesses and countries. They negatively affect the health care systems, tourism, productivity and livelihood (WHO, 2013; Grace et al., 2015a).

Review of literature indicates that food safety is a growing concern within the ethnic food industry (Rudder, 2006; Roberts et al., 2011; Njomo, 2012, 2013; Stenger et al., 2014). In United Stated and Europe alone the outbreaks related to ethnic food increased from 3\% to $11 \%$ between 1990 to 2000 (Quinlan, 2013). This is attributed to poor hygienic practices (Grace et al., 2015b; Harris et al., 2015); poor quality of food (Rudder, 2006; Njomo, 2012, 2013), and failure to comply with food safety regulations (Roberts et al., 2011; Harris et al., 2015).

Good employee hygienic food handling practices are critical in preventing cross contamination of food, equipment and utensils (Harris et al., 2015). However, many studies show that employees in the ethnic food restaurants (Rudder, 2006; Roberts et al., 2011; Grace et al., 2015b; Harris et al., 2015) tend not follow critical good hygienic practices. For example a study conducted in Greater Manchester by Rudder (2006), found that majority of ethnic retailers failed to meet the minimum standard of food hygiene and lacked the necessary knowledge required to implement effective food safety measures. In fact, majority of ethnic retailers that were studied were considered a high risk and therefore suspected to be the cause for food borne illnesses such as Escherichia Coli. Roberts et al. (2011) also observed that a number of violations in the ethnic food restaurants were directly related to poor employee hygienic practices.

According to Quinlan (2013), dirty floors, work surfaces, equipment; and lack of disinfectants were among the top hygienic concerns within the ethnic food restaurants in a study that was conducted in the UK. Poor hygienic practices have been associated with cultural food handling methods and beliefs, which are often in contrary with the food safety guidelines. This is due to lack of knowledge and skills to implement effective monitoring systems for personal hygiene and food handling practices (Harris, 2015). Grace et al. (2015b) are of the view that ethnic food restaurant operators and employees often lack information with regards to good hygiene practices and basic resources such as tap water, power supply and waste disposal facilities. 
The quality of food sold by ethnic retailers has been identified as being of poor quality from a food safety perspective (Rudder, 2006; Njomo, 2012, 2013). For example, food safety has been mentioned as being problematic amongst Hispanic families residing in United States. It has also, been shown that immigrants who attempt to maintain their original food culture experience a high number of food borne illnesses incidences (Stenger et al., 2014). This has been shown to be true especially where the majority of these immigrants preferred and obtained their food from ethnic food retailers even where ethnic foods are available in the mainstream supermarkets.

In South Africa majority $(55 \% ; n=225)$ of sub-Saharan immigrants that participated in a study that was conducted in the Western Cape, complained about the poor quality of food sold by ethnic retailers (Njomo, 2012). Njomo (2013) goes on to suggest that food at these shops was often decomposed, smelt and taste bad. Ethnic retailers interviewed by Njomo (2013) in Cape Town attributed the poor quality of food to poor preservation methods used to preserve the food in question, the duration it takes, lack of skills and resources to transport ethnic foods from supplying countries to South Africa. This could also be because the value chain within the ethnic food retailers in South Africa is already complex and extended. It is known that complex value chains make food vulnerable to contamination (Oguttu et al., 2014). This coupled with poor resources that are a characteristic of the informal sector like ethnic markets, could compromise food quality even further. Of noteworthy though, is that there is paucity of studies that have assessed the microbiological quality of foods in the ethnic markets and restaurants (Roberts et al., 2011) especially in South Africa.

Available research suggests that majority of the ethnic food markets, and restaurants fail to comply with food safety regulations (Rudder, 2006; Roberts et al., 2011; Harris et al., 2015). For example in a study by Rudder (2006), a number of the ethnic retailers failed to meet the minimum standards of food legislation which stated that food premises should have soap, proper drying methods and a basin. In addition, majority of the structures in which these businesses operated were in breach of the legislation for structures selling food. They had damaged equipment, poor ventilation, broken floors and ceiling.

Failure to adhere to regulatory requirements was observed in studies conducted in the United States by Roberts et al. (2011) and Harris et al. (2015), which analysed inspection health reports. Even within the ethnic markets, variations in adherence to regulatory requirements have been observed. For example, Roberts (2011) observed that independent ethnic markets had more critical and non-critical violations recorded, as compared to chain-ethnic restaurants and non-ethnic restaurants. Moreover, Harris et al. (2015) concluded that failure by ethnic restaurants to comply with the food legislation as stipulated by the United States' Food and Drug Administration is a national issue. Non-compliance was attributed to cultural differences, and inability of restaurant operators to comprehend government regulations (Roberts et al., 2011; Harris et al., 2015). Poor communication of food safety regulations due to language barriers has also been blamed for non-compliance of ethnic food markets and restaurants (Rudder, 2006; Roberts et al., 2011). Language barriers makes it difficult to train the actors within the sector (Rudder, 2006). These findings suggest that there is a need for cultural appropriate training material (Harris et al., 2015). Moreover, to address the language barrier the training material should be made available in the native language of the owner of the ethnic restaurant (Roberts et al., 2011). 
Based on the preceding section, it is clear that food safety is a major problem within the ethnic food markets. However, since food safety concerns associated with ethnic markets have not been documented, studies to ascertain if there are any food safety concerns in the ethnic retail industry, especially in a country like South Africa where this industry is still in its infancy and remains the only source of ethnic foods for subSaharan immigrants are needed. Furthermore, a study that looks at food safety within the ethnic retail sector would act as a preventative measure of food borne illnesses within this growing section of the South African population. This could thus reduce the resources that would be required to treat the outbreak of illnesses if the matter is not given the attention. Moreover, future research on food safety knowledge amongst the ethnic restaurant and ethnic food markets managers will enable the authorities to develop appropriate training manuals.

\section{Pressure from children to adopt host country's food}

Pressure from children to adopt host country's food has been described as one of the challenges immigrant mothers experience upon resettlement. This is because, when children of immigrants get exposed to the host country's food culture during the school going age, they tend to adopt the eating habits of the host country (Vue et al., 2011; Mannion et al., 2014; Terragni et al., 2014; Wilson and Renzaho, 2014). According to Vue et al. (2011) and Dharod et al. (2013) children are usually easily acculturated than their parents due to peer pressure, media and environment. The result is that most children immigrants tend to prefer the host country's food over the traditional food of the countries their parents came from (Vue et al., 2011; Dharod et al., 2013; Mannion et al., 2014). This causes frustration amongst mothers who lack knowledge and do not trust the food culture of the host country.

Terragni et al. (2014) observed that the cause of the easy acculturation among children of immigrants, is children become reluctant to take food to school that is different from what the rest of the children bring in their lunch boxes. This is a problematic, because as mentioned above the immigrant mothers lack knowledge and do not trust host country's food culture. Subsequently most mothers are often conflicted between the desires to indulge children's preferences versus that of wanting to uphold traditional eating patterns (Mannion et al., 2014).

The other problem associated with the pressure from children to adopt the host country's food is related to convenience. For example, in the study done in Australia by Wilson and Renzaho (2014), the refusal of children to eat their traditional food was associated with the inconvenience of carrying the food to school that required reheating. The problem that arises from this, is that parents often choose unhealthy foods as a response to the demands of their children (Vue et al., 2011). This could be associated with not being familiar with the host country's food culture discussed in earlier sections in this paper. Dharod et al. (2013) supports this view by noting that such children tend to prefer fast foods as opposed to the traditional ethnic foods that the parents want them to eat or take to school. This could have dire consequences for dietary changes and malnutrition. In view of this, there is a need to investigate whether this is true for the immigrants from sub-Saharan Africa living in South Africa. 


\section{Role of religion in determining immigrant's food choices in host countries}

Religious beliefs play a major role in shaping the dietary patterns of people. Certain religious affiliations often result into what is known as food avoidance, a situation whereby members are prohibited from consuming certain foods. Generally, food avoidances are either temporal or permanent. However, those that are due to religious affiliations tend to be permanent because the foods in question are regarded as being impure or hold a sentimental value. The two most known religions that endorse permanent food prohibitions are Muslims and Hindus (Hartog, 2006). Fundamentally, food avoidances define what food is and what is acceptable to consume. According to Jacobus and Jalali (2011) food avoidances are the reason why immigrants could experience food insecurity despite the availability of the traditional ingredients in host countries (Jacobus and Jalali, 2011).

For example, in the case of Muslims who have to eat halal food, they are frequently not sure if the food they are buying is actually halal or not, which forces them to restrict their food baskets to fewer food items (Garnweidner et al., 2012; Terragni et al., 2014). This lack of trust causes Muslim immigrants to exclude all foods affected by religious rules from their diets (Garnweidner et al., 2012; Terragni et al., 2014). This phenomenon of religiously "safe" food was also highlighted in a study that was conducted amongst the African immigrant population residing in Lewiston. Due to issues related to trust, most respondents in the study preferred small ethnic markets run by fellow compatriots. Apart from exclusion of pork, meat for Muslims has to be slaughtered in a certain manner by trained Muslim men (Jacobus and Jalali, 2011; Harrow, 2013). Furthermore separate utensils have to be used for Halal otherwise if contaminated it becomes Haram (Harrow, 2013). Haram refers to all the food that is forbidden according Islamic food laws and customs. However, the availability of these special personnel is usually a problem in host countries. As a result, halal products have to be imported from abroad. This in turn inflates the costs of such foods thus limiting the availability and access of halal products due to imports costs and lack of competition. Additionally, it has been reported that most Muslims also prefer to source imported products such as rice, spices, dried fruits and condiments from these halal speciality shops just to ensure that they are not haram (Jacobus and Jalali, 2011).

Similar to Islamic religion, Hindus have numerous permanent food avoidances (Hartog et al., 2006; Harrow, 2013). However contrary to Islamic belief, Hindus avoid certain food not because they are considered unclean but due to respect (Hartog et al., 2006; Harrow, 2013). A typical example of this is a cow which is highly respected in Hindu culture. Therefore, Hindus do not kill cows for food and they avoid all beef or beef products (Hartog et al., 2006; Harrow, 2013). Other food avoidances include alcohol and all animal products including rennet, eggs or gelatine of animal origin. Furthermore, due to the avoidance of beef and beef related products prevention of cross contamination during food preparation, cooking utensils becomes very crucial. Therefore any such any food suspected of having been contaminated is completely avoided. Similarly like when preparing food for Muslims, separate utensils and food preparation areas should be used when cooking food for Hindus. Consequently, fear of cross-contamination has been cited as a the main reason why majority of Hindus avoid eating from public places. Furthermore, there are certain rituals that need to be adhered to when preparing, cooking and serving food to Hindus (Harrow, 2013). Therefore cynicism alluded to in the preceding section could result especially when food is sold by 
people outside this religious group. Consequently, this could have food inaccessibility implications and adverse effect food security.

Based on this review it is apparent that religious beliefs are one of the barriers to accessing sufficient food amongst immigrants especially if religious beliefs of the host country differ vastly from their own country of origin. In South Africa for example majority $(85,5 \%)$ of the population are Christians, with only $2 \%$ and $1 \%$ of the population affiliated to Muslims and Hindus religions respectively (Statistics South Africa, 2014a). This could have a negative impact on the availability and accessibility of appropriate food for people belonging to these groups. Consequently, it could have adverse implications on the health of immigrants belonging to these religious groups as it limits food choices resulting into monotonous diets. The most notable fact about this is the exclusion of meat by most immigrant's due to the fear of eating food that is religiously unacceptable (Terragni et al., 2014). Consuming a limited variety of food is associated with malnutrition. Exclusion of meat without proper replacement could result into nutrient deficiencies such as protein, iron and vitamin A deficiencies (Schönfeldt and Hall, 2012). In South Africa, there is a need for studies that assess the impact of religious reasons on immigrant's ability to access food, in particular how pre-migration religious beliefs influence food choices among immigrants upon resettlement.

\section{Conclusion and recommendations}

This review highlights several factors that limit dietary choices of immigrants upon resettlement in new countries. These include climate change, socio-economic status, new shopping environment, negative perceptions towards host country's food, acculturation with ease by their children to the host country's food, and language barriers. This review also identifies several factors that impede access to culturally acceptable foods by immigrants. These factors include inaccessibility, and poor quality of ethnic foods and religious factors. These are unique factors that play a major role in determining the household food security of immigrants upon resettlement. Limited understanding of these factors by the host country's authorities hampers efforts to protect immigrants from food insecurity, and places immigrants at the risk of developing lifestyle diseases, which in turn could put tremendous pressure on the public health systems of the host countries. This could also jeopardize global efforts to contain Non Communicable Diseases (NCD) by 2025, as stipulated in the Global Status Report on Non Communicable Diseases of 2014 (WHO, 2014).

The present study revealed that there is scantiness of dietary related studies on SubSaharan African immigrants migrating within the continent. This is despite the fact that majority of migration in Sub-Saharan Africa takes place within the continent. Available Studies have been limited to countries like Canada and United States.

Moreover, statistics indicate that the number of Sub-Saharan immigrants living in South Africa is on the increase. In view of this, research is needed to establish dietary patterns of these immigrants and the challenges they face in terms of accessing their foods. An understanding of immigrant's dietary patterns and challenges could assist the health professionals and policy makers to design tailor made nutrition programs and provide maximum nutritional health equity. This will not only improve their health status, but also has potential to reduce the burden on the health care system that could ensue if this matter is was left unattended. Available evidence suggests that though 
ethnic markets are the only source of ethnic foods for Sub-Saharan immigrants living in South Africa, there is paucity of studies on ethnic food markets.

Despite diverse food patterns within the sub-Saharan region, ethnic food preferences, and the availability and accessibility of ethnic food to immigrants within the continent has not been fully investigated. Therefore, further studies are also required to establish availability and accessibility of immigrant's ethnic / traditional food in South Africa.

Additionally, studies to verify the prevalence of food related challenges and factors that impede on sub-Saharan immigrants accessing their traditional food in South Africa are needed. These studies should also establish the relationship between these factors and food insecurity within the immigrant population. In South Africa, though food insecurity studies have not traditionally been tracked by citizenship status, there is an urgent need for evidence-based research on prevalence, causes and potential consequences of food insecurity among all sectors of the South African population including immigrants.

Further research on food safety from the ethnic food markets is another area that merits consideration and further research.

\section{REFERENCES}

[1] Adepoju, A. (2008): Current African Issues - Migration in sub-Saharan Africa. - The Nordic Africa Institute, Uppsala.

[2] Anderson, L., Hadzibegovic, D. S., Moseley, J. M., Sellen, D. W. (2014): Household food insecurity shows associations with food intake, social support utilization and dietary change among refugee adult caregivers resettled in the United States. - Ecology of Food and Nutrition 53(3): 312-32.

[3] Arksey, H., O’Malley, L. (2005): Scoping studies: towards a methodological framework. - International Journal of Social Research Methodology: Theory and Practice 8(1): 1932.

[4] Berjak, P., Bartles, P., Benson, E. E., Harding, K., Mycock, D. J., Pammenter, N. W., Sershen, Wesley-Smith, J. (2011): Cryoconservation of South African plant genetic diversity. - In Vitro Cellular \& Developmental Biology-Plant 47(1): 65-81. https://link.springer.com/content/pdf/10.1007\%2Fs11627-010-9317-4.pdf

[5] Deng, F., Zhang, A., Chan, C. (2013): Acculturation, dietary acceptability, and diabetes management among Chinese in North America. - Frontiers in Endocrinology 4(108): 17.

[6] Dharod, J. M., Croom, J., Sady, C. G., Morrell, D. (2011): Dietary intake, food security, and acculturation among Somali refugees in the United States: results of a pilot study. Journal of Immigrant \& Refugee Studies 9: 82-97.

[7] Dharod, J. M., Xin, H., Morrison, S. D., Young, A., Nsonwu, M. (2013): Lifestyle and food-related challenges refugee groups face upon resettlement: do we have to move beyond job and language training programs? - Journal of Hunger \& Environmental Nutrition 8(2): 187-199.

[8] FAO (2006): Policy Brief. Issue 2: Food Security. FAO, Rome. http://www.fao.org/forestry/(1312)8-0e6f36f27e0091055bec28ebe830f46b3.pdf [2004, May 15].

[9] Garnweidner, L. M., Terragni, L., Pettersen, K. S., Mosdøl, A. (2012): Perceptions of the host country's food culture among female immigrants from Africa and Asia: aspects relevant for cultural sensitivity in nutrition communication. - Journal of Nutrition Education and Behavior 44(4): 335-42. 
[10] Grace, D., Roesel, K., Kohei, M., Kurwijila, L., Saskia, H., Girma, Z., Matusse, H. (2015a): Introduction. - In: Roesel, K., Grace, D. (eds.) Food Safety and Informal Markets. Animal Products in Sub-Saharan Africa. 1st ed. Routledge, Abington.

[11] Grace, D., Makita, K., Kang'ethe E., Bonfoh, B., Roesel, K. (2015b): Taking Food Safety to Informal Markets. - In: Roesel, K., Grace, D. (eds.) Food Safety and Informal Markets. Animal Products in Sub-Saharan Africa. 1st ed., pp. 11-22. Routledge, Abington.

[12] Hadley, C., Patil, C. L., Nahayo, D. (2010): Difficulty in the food environment and the experience of food insecurity among refugees resettled in the United States. - Ecology of Food and Nutrition 49(5): 390-407.

[13] Harris, K. J., Murphy, K. S., DiPietro, R. B., Rivera, G. L. (2015): Food safety inspections results: A comparison of ethnic-operated restaurants to non-ethnic-operated restaurants. - International Journal of Hospitality Management 46: 190-199.

[14] Harrow, M. (2013): Working Effectively with Minority Ethnic Food Businesses: Resource Handbook. - YFA Consultancy and Food Standards Agency, London.

[15] Hartog, A. P. den, Staveren, W. A. van, Brouwer, I. D. (2006): Food Habits and Consumption Patterns in Developing Countries. - Wageningen Academic Publishers, Wageningen, The Netherlands.

[16] Jacobus, M. V., Jalali, R. (2011): Challenges to food access among Lewiston's African immigrants. - Maine Policy Review 20 (1): 151-158.

[17] Kiptinness, C., Dharod, J. M. (2011): Bhutanese refugees in the United States: Their dietary habits and food shopping practices upon resettlement. - Journal of Hunger \& Environmental Nutrition 6 (1): 75-85.

[18] Lesser, I., Gasevic, D., Lear, S. (2014): The association between acculturation and dietary patterns of South Asian immigrants. - Plos One 9(2): 1-6.

[19] Lindsay, K. L., Gibney, E. R., McNulty, B. A., McAuliffe, F. M. (2014): Pregnant immigrant Nigerian women: an exploration of dietary intakes. - Public Health 128(7): 647-53.

[20] Mannion, C., Raffin-Bouchal, S., Henshaw, C. J. (2014): Navigating a strange and complex environment: experiences of Sudanese refugee women using a new nutrition resource. - International Journal of Women's Health 6: 411-22.

[21] McMichael, C., Barnett, J., McMichael, A. J. (2012): An II wind? Climate change, migration and health. - Environmental Health Perspectives 120(5): 645-654. https://www.ncbi.nlm.nih.gov/pmc/articles/PMC(3346)786/pdf/ehp.1104375.pdf.

[22] McMichael, C. (2015): Climate change-related migration and infectious disease. Virulence 6(6): 548-553. http://www.tandfonline.com/doi/pdf/10.1080/21505594.2015.1021539?needAccess=true.

[23] Njomo, L. M. (2012): Satisfying the indigenous food needs of sub-Saharan African immigrants in South Africa: A food consumption behaviour model for South Africa's leading supermarket chains. - African Journal of Business Management 6(25): (7557)7568.

[24] Njomo, L. M. (2013): Examining the impacts of ethnic grocery shops on the food consumption behaviour of sub-Saharan African immigrants in South Africa. - Universal Journal of Education and General Studies 2(4): 142-149.

[25] Oguttu, J. W., McCrindle, C. M. E., Makita, K., Grace, D. (2014): Investigation of the food value chain of ready-to-eat chicken and the associated risk for staphylococcal food poisoning in Tshwane Metropole, South Africa. - Food Control 45: 87-94.

[26] Okafor, M., Carter-Pokras, O., Zhan, M. (2014): Greater Dietary acculturation (dietary change) is associated with poorer current self-rated health among African immigrant adults. - Journal of Nutrition Education and Behavior 46(4): 226-235.

[27] Pendleton, W., Crush, J., Nickanor, N. (2014): Migrant Windhoek: Rural-Urban Migration and Food Security in Namibia. - Urban Forum 25(2): 191-205. http://doi.org/10.1007/s12132-014-9220-x 
[28] Popovic-Lipovac, A., Strasser, B. (2015): A review on changes in food habits among immigrant women and implications for health. - Journal of Immigrant and Minority Health/Center for Minority Public Health 17: 582-590.

[29] Quinlan, J. J. (2013): Foodborne illness incidence rates and food safety risks for populations of low socioeconomic status and minority race/ethnicity: a review of the literature. - International Journal of Environmental Research and Public Health 10(8): 3634-3652.

[30] Ratha, D., Shaw, W. (2007): South-South Migration and Remittances. (World Bank Working Paper No. 102). - World Bank, Washington DC, USA.

[31] Renzaho, A. M. N., Burns, C. (2006): Post-migration food habits of sub-Saharan African migrants in Victoria: A cross-sectional study. - Nutrition Dietetics 63(2): 91-102.

[32] Roberts, K., Kwon, J., Shanklin, C., Liu, P., Yen, W.-S. (2011): Food safety practices lacking in independent ethnic restaurants. - Journal of Culinary Science \& Technology 9(1): $1-16$.

[33] Ross, W. L., Gallego, D. F., Pérez, R., Amber, E., Fiedler, H., Lartey, A., Sandow, A. (2016): Dietary patterns in Liberian refugees in Buduburam, Ghana. - Maternal \& Child Nutrition 2016(June): 1-10.

[34] Rudder, A. (2006): Food safety and the risk assessment of ethnic minority food retail businesses. - Food Control 17(3): 189-196.

[35] Sanou, D., O’Reilly, E., Ngnie-Teta, I., Batal, M., Mondain, N., Andrew, C., Newbold, B. K., Bourgeault, I. L. (2014): Acculturation and nutritional health of immigrants in Canada: a scoping review. - Journal of Immigrant and Minority Health/Center for Minority Public Health 16(1): 24-34.

[36] Satia, J. (2010): Dietary acculturation and the nutrition transition: an overview. - Applied Physiology, Nutrition, and Metabolism = Physiologie appliquée, nutrition et métabolisme 35(2): 219-23.

[37] Schönfeldt, H. C., Hall, N. (2012): Red Meat in Nutrition and Health: Communicating Current Science about Red Meat as Part of a Healthy South African Diet. - Institute of Food, Nutrition and Well-Being, Pretoria.

[38] Shackelford, E. (2010): Issue Brief : Immigration and Socioeconomic Status. https://academiccommons.columbia.edu/download/.../shackelford_issue_brief.pdf

[39] Statistics South Africa. (2013): Discussion Document. Documented Immigrants in South Africa (2011). - Statistics South Africa, Pretoria.

[40] Statistics South Africa (2014a): General Household Survey 2013. Statistical Release P0318. - Statistics South Africa, Pretoria.

[41] Statistics South Africa (2014b): Documented Immigrants in South Africa, 2013. Statistics South Africa, Pretoria.

[42] Stenger, K. M., Ritter-Gooder, P. K., Perry, C., Albrecht, J. A. (2014): A mixed methods study of food safety knowledge, practices and beliefs in Hispanic families with young children. - Appetite 83: 194-201.

[43] Terragni, L., Garnweidner, L. M., Pettersen, K. S., Mosdøl, A. (2014): Migration as a turning point in food habits: the early phase of dietary acculturation among women from South Asian, African, and Middle Eastern Countries living in Norway. - Ecology of Food and Nutrition 53(3): 273-91.

[44] Vahabi, M., Damba, C. (2013): Perceived barriers in accessing food among recent Latin American immigrants in Toronto. - International Journal for Equity in Health 12(1): 1.

[45] Vahabi, M., Damba, C., Rocha, C., Montoya, E. C. (2011): Food insecurity among Latin American recent immigrants in Toronto. - Journal of Immigrant and Minority Health 13(5): 929-939.

[46] Vue, W., Wolff, C., Goto, K. (2011): Hmong food helps us remember who we are: perspectives of food culture and health among Hmong women with young children. Journal of Nutrition Education and Behavior 43(3): 199-204. 
[47] WHO (2013): Advancing Food Safety Initiatives Strategic Plan for Food Safety 20132022. - World Health Organization, Geneva.

[48] WHO (2014): Global Status Report On Noncommunicable Diseases 2014. World Health Organization, Geneva.

http://apps.who.int/iris/bitstream/10665/148114/1/9789241564854_eng.pdf?ua=1

[49] Wilkinson, K. (2015): Do five million immigrants live in SA. - Mail \& Guardian, 6 May. https://mg.co.za/article/2015-05-06-do-5-million-immigrants-live-in-sa

[50] Wilson, A., Renzaho, A. (2014): Intergenerational differences in acculturation experiences, food beliefs and perceived health risks among refugees from the Horn of Africa in Melbourne, Australia. - Public Health Nutrition (4): 1-13. 


\section{APPENDIX}

Appendix 1. Summary of sample size and study areas of studies included in the review

\begin{tabular}{|c|c|c|c|}
\hline Article & Study population & Sample size & Study area \\
\hline 1. Adepoju, 2008 & $\begin{array}{l}\text { Sub-Saharan immigrants: } \\
\text { This is not a research article, } \\
\text { but a review of the migration } \\
\text { trends in sub-Saharan Africa }\end{array}$ & Not applicable & Not applicable \\
\hline $\begin{array}{l}\text { 2. Anderson et al., } \\
2014\end{array}$ & Sudanese & 49 & Atlanta, United States \\
\hline $\begin{array}{l}\text { 3. Arksey and } \\
\text { O'Malley, } 2005\end{array}$ & 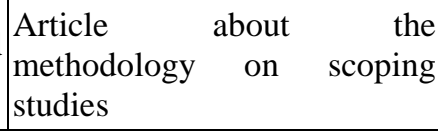 & Not applicable & Not applicable \\
\hline 4. Berjak et al., 2011 & $\begin{array}{l}\text { Review article about studies } \\
\text { conducted on conservation of } \\
\text { plant genetic diversity }\end{array}$ & Not applicable & South Africa \\
\hline 5. Deng et al., 2013 & Chinese immigrants & & North America \\
\hline 6. Dharod et al., 2011 & Somali refugees & 35 & United States \\
\hline 7. Dharod et al., 2013 & $\begin{array}{l}\text { Refugees (country of origin } \\
\text { not specified) }\end{array}$ & 13 & United States \\
\hline 8. FAO, 2006 & & & \\
\hline $\begin{array}{l}\text { 9. Garnweigner et al., } \\
2012\end{array}$ & African and Asian immigrants & 21 & Oslo, Norway \\
\hline 10. Grace et al., 2015a & $\begin{array}{l}\text { Introduction to a book about } \\
\text { informal markets }\end{array}$ & Not applicable & $\begin{array}{l}\text { Studies conducted in } \\
\text { sub-Saharan African } \\
\text { countries }\end{array}$ \\
\hline 11. Grace et al., 2015b & $\begin{array}{l}\text { A chapter in a book on } \\
\text { informal markets }\end{array}$ & Not applicable & $\begin{array}{l}\text { Studies conducted in } \\
\text { sub-Saharan African } \\
\text { countries }\end{array}$ \\
\hline 12. Hadley et al., 2012 & $\begin{array}{l}\text { Refugees including countries/ } \\
\text { ethnicities such as Sierra } \\
\text { Leone, Liberia, Ghana, } \\
\text { Somalia, Togo, } \\
\text { Meskhetian Turk }\end{array}$ & 281 & United States \\
\hline 13. Harris et al., 2015 & $\begin{array}{l}\text { Reviewed data on number of } \\
\text { inspections and violations at } \\
\text { ethnic and non-ethnic } \\
\text { restaurants }\end{array}$ & 34,259 restaurants & United States \\
\hline 14. Harrow, 2013 & \multicolumn{2}{|c|}{$\begin{array}{l}\text { Not a research article but a handbook that assisted in } \\
\text { defining some of the terminologies used in the } \\
\text { manuscript }\end{array}$} & United Kingdom \\
\hline 15. Hartog et al., 2006 & \multicolumn{2}{|c|}{$\begin{array}{l}\text { Not a research article but a handbook that assisted in } \\
\text { defining some of the terminologies used in the } \\
\text { manuscript }\end{array}$} & \\
\hline $\begin{array}{l}\text { 16. Jacobus and Jalali, } \\
2011\end{array}$ & African immigrants & 9 (in depth interviews) & Lewiston \\
\hline $\begin{array}{ll}\text { 17. Kiptinness } & \text { and } \\
\text { Dharod, } 2011 & \\
\end{array}$ & Bhutanese refugees & 14 & United states \\
\hline 18. Lesser et al., 2014 & South Asian immigrants & 207 & Canada \\
\hline 19. Lindsay et al., 2014 & Nigerian pregnant women & 52 & Dublin, Ireland \\
\hline 20. Mannion et al., 2014 & Sudanese refugee women & 8 & Calgary, Canada \\
\hline
\end{tabular}




\begin{tabular}{|c|c|c|c|}
\hline $\begin{array}{l}\text { 21. McMichael et al., } \\
2012\end{array}$ & $\begin{array}{l}\text { Review of previous studies on } \\
\text { refugees, people r on } \\
\text { resettlement schemes and } \\
\text { those who migrate to urban } \\
\text { areas }\end{array}$ & Not applicable & Not specified. \\
\hline 22. McMichael C., 2015 & Review & Not applicable & $\begin{array}{l}\text { Drawing examples } \\
\text { from Bangladesh, } \\
\text { China, the Horn of } \\
\text { Africa and the Greater } \\
\text { Mekong Sub region }\end{array}$ \\
\hline 23. Njomo, 2012 & Sub-Saharan immigrants & 409 & $\begin{array}{lll}\text { Cape } & \text { Town, South } \\
\text { Africa } & & \\
\end{array}$ \\
\hline 24. Njomo, 2013 & Sub-Saharan immigrants & 409 & \begin{tabular}{|lll} 
Cape & Town, & South \\
Africa & & \\
\end{tabular} \\
\hline 25. Oguttu et al., 2014 & Informal food markets & 100 food samples & $\begin{array}{l}\text { Tshwane Metropole, } \\
\text { South Africa }\end{array}$ \\
\hline 26. Okafor et al., 2014 & African immigrants & 763 & United States \\
\hline $\begin{array}{l}\text { 27. Pendleton et al., } \\
2014\end{array}$ & Rural-urban immigrants & 144 & Windhoek, Namibia \\
\hline $\begin{array}{l}\text { 28. Popovic-Lipovac et } \\
\text { al., } 2015\end{array}$ & Review article & 179 articles & $\begin{array}{l}\text { Studies conducted in } \\
\text { Canada, USA, UK, } \\
\text { Sweden, Germany and } \\
\text { Netherlands }\end{array}$ \\
\hline 29. Quinlan, 2013 & $\begin{array}{l}\text { Review article on food safety } \\
\text { risks for minority and low } \\
\text { socioeconomic } \\
\text { population }\end{array}$ & Not specified & $\begin{array}{lll}\text { Studies } & \text { conducted in } \\
\text { United } & \text { States and } \\
\text { Europe } & & \end{array}$ \\
\hline $\begin{array}{l}\text { 30. Ratha and Shaw, } \\
2007\end{array}$ & South-South Migration & $\begin{array}{|lrr|}\text { Data } & \text { from } & 167.6 \\
\text { million } & \text { immigrants } \\
\text { across } & \text { the } & \text { globe }\end{array}$ & Global trends \\
\hline $\begin{array}{l}\text { 31. Renzaho and Burns, } \\
2006\end{array}$ & Sub-Saharan African migrants & 139 households & Victoria \\
\hline 32. Roberts et al., 2011 & $\begin{array}{l}\text { Ethnic and non-ethnic } \\
\text { restaurants }\end{array}$ & 924 restaurants & Kansas, United States \\
\hline 33. Ross et al., 2016 & \begin{tabular}{|lll} 
Liberian & refugees \\
Ghanians & & \\
\end{tabular} & 480 & Buduburam, Ghana \\
\hline 34. Rudder, 2006 & Ethnic restaurants & 40 ethnic restaurants & $\begin{array}{l}\text { Borough of Bolton, } \\
\text { Greater Manchester. }\end{array}$ \\
\hline 35. Sanou et al., 2014 & A review & 49 articles & Canada \\
\hline 36. Satia, 2010 & A review & 28 articles & North America \\
\hline $\begin{array}{l}\text { 37. Schönfeldt and Hall, } \\
2012\end{array}$ & $\begin{array}{l}\text { A book on Red Meat in } \\
\text { Nutrition and Health }\end{array}$ & Not applicable & South Africa \\
\hline 38. Shackleford, 2010 & Policy brief not a research artic & & United States \\
\hline $\begin{array}{l}\text { 39. Statistics } \\
\text { Africa, } 2013\end{array}$ & $\begin{array}{l}\text { Discussion document } \\
\text { Documented immigrants }\end{array}$ & Not applicable & South Africa \\
\hline $\begin{array}{l}\text { 40. Statistics South } \\
\text { Africa, 2014a }\end{array}$ & General Household Survey & Not applicable & South Africa \\
\hline $\begin{array}{l}\text { 41. Statistics South } \\
\text { Africa, 2014b }\end{array}$ & $\begin{array}{l}\text { Discussion document } \\
\text { Documented immigrants }\end{array}$ & Not applicable & South Africa \\
\hline 42. Stenger et al., 2014 & Hispanic families & 52 & Midwestern state \\
\hline
\end{tabular}




\begin{tabular}{l|l|l|l}
\hline $\begin{array}{l}\text { 43. Terragni et al., 2014 } \\
\begin{array}{l}\text { 44. Vahabi and Damba, } \\
2013\end{array}\end{array}$ & $\begin{array}{l}\text { Women from South Asia, } \\
\text { African, and Middle East }\end{array}$ & 21 & Norway \\
\hline $\begin{array}{l}\text { 45. Vahabi et al., 2011 } \\
\text { 46. Vue et al., 2011 }\end{array}$ & Latin American immigrants & 70 & Toronto \\
\hline $\begin{array}{l}\text { 47. WHO, 2013 } \\
\text { Hot a research article but a } \\
\text { strategic plan about advancing } \\
\text { food safety initiatives }\end{array}$ & 70 & Not applicable & Toronto \\
\hline $\begin{array}{l}\text { 48. WHO, 2014 } \\
\text { Not a research article but a } \\
\text { global status on the } \\
\text { Noncommunicable diseases }\end{array}$ & Not applicable & Not applicable \\
\hline $\begin{array}{l}\text { 49. Wilkinson, 2015 } \\
\text { 50. Wilson } \\
\text { Renzaho, 2014 }\end{array}$ & $\begin{array}{l}\text { Newspaper article based on immigrants, living South Africa } \\
\text { Johannesburg }\end{array}$ & \begin{tabular}{l} 
Horn of Africa immigrants \\
\hline
\end{tabular}
\end{tabular}

